\title{
Helicobacter felis
}

National Cancer Institute

\section{Source}

National Cancer Institute. Helicobacter felis. NCI Thesaurus. Code C14330.

A species of helix-shaped, Gram-negative Helicobacter in the phylum Proteobacteria that has been shown to be a human pathogen. $\mathrm{H}$. felis infection induces chronic gastric inflammation. 